\title{
Impact of Food Processing on the Implementation of Dietary Guidelines
}

\author{
G. Frisch I. Elmadfa \\ Institute of Nutritional Sciences, University of Vienna, Vienna, Austria
}

\author{
Key Words \\ Community nutrition - Nutrient content optimization • \\ Professional food processing
}

\begin{abstract}
Community nutrition offers a wide range of possibilities to increase the health-promoting potential of meals. Yet, the potential for increasing the nutritional quality and the health-promoting value of food is not fully utilized, particularly in the setting of canteen kitchens. There are more than 3,000 canteen kitchens in Austria, and their meal service may have a considerable impact on the well-being of approximately 1.5 million consumers. Nutrient-based dietary guidelines act as an interface between theory and practice and form the basis for the development of recipes and for professional menu planning. In this regard, food processing plays a central role for the implementation of dietary guidelines. It is a common challenge for nutritionists and cooks to provide meals that are both tasty and healthy. Optimization with regard to the health value of community nutrition means reorientation and is composed of two steps: (1) optimization of nutrient and energy contents of menus through a well-balanced diet composition and (2) best-possible preservation of nutrients through professional food processing. Nutrient content optimization in food needs to consider all areas of community nutrition, including a target group oriented nutrient calculation, as well as planning and develop-
\end{abstract}

ment of tasty and healthy meals and the highest possible nutrient retention during the entire food preparation process.

\section{Introduction}

It is estimated that seven out of ten deaths in Austria were caused by nutrition-related diseases in 2004 alone. In order to reduce this number, comprehensive healthpromoting programs are necessary (fig. 1) [1].

The Austrian Nutrition Report 2003 showed insufficient intake levels of some nutrients across all age groups despite an abundance of food and an excessive energy supply. Thus, it is necessary to optimize the availability of individual nutrients already on the level of food processing [2].

The potential for increasing the nutritional quality and the health-promoting value of food is not yet utilized. A close collaboration between nutritional sciences, food industry and catering systems appears to be a promising approach for the optimization of meals with regard to their nutritional value.

According to an investigation carried out by Gastro Obsearcher in cooperation with the Association of the Austrian Food Caterers (AGÖ Arbeitsgemeinschaft Grossküchen Österreichs) in 2005, there are more than

\section{KARGER \\ Fax +4161306 1234 \\ E-Mail karger@karger.ch}

www.karger.com
(C) 2007 S. Karger AG, Basel

0250-6807/07/0518-0050\$23.50/0

Accessible online at:

www.karger.com/anm
Georg Frisch

Institute of Nutritional Sciences, University of Vienna

Althanstrasse 14, AT-1090 Vienna (Austria)

Tel. +43 14277 54911, Fax +43 142779549

E-Mail georg.frisch@univie.ac.at 


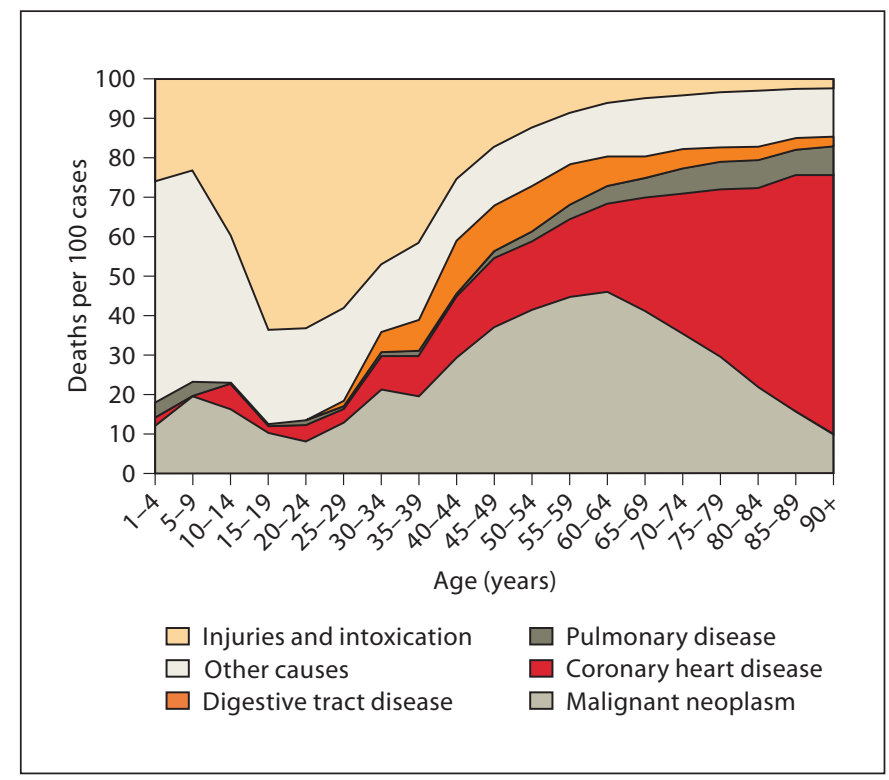

Fig. 1. Causes of deaths in Austria, 2004 [1].

3,000 canteen kitchens in Austria [3]. The work done in these kitchens has a considerable impact on the well-being of approximately 1.5 million eaters. Three quarters of the people utilizing the services of community nutrition regularly are employees (1.2 million). A remarkable share - at least from a health-promoting dimension - is also shown in children $(380,000)$ and the elderly $(70,000)$ [4].

Nowadays, it is becoming more and more common for people to use the services of community nutrition for a long time span - from kindergarten to retirement home. Thus, it is evident that community nutrition plays an important role in public health.

\section{Optimization of the Nutritional Health Value Requires Reorientation}

During the past years, community nutrition and catering systems have been rapidly technologically modernized; nevertheless, the nutritional quality of the produced meals has not improved to the same extent. A possible explanation could be that many food manufacturers and cooks still think that meals need to be tasteful but not expensive. Thus, the nutritional value of food plays only a minor role.

Optimization with regard to the health value of community nutrition means reorientation. The sensoric properties and the health value of the food should be of equal importance. This is a common challenge for nutritionists and cooks.

The nutrient-based intake recommendations represent the interface between scientific research and cooking practice. The reference values for energy and nutrient intake, for example the DACH reference values [5], provide important and practical guidelines for the planning of menus, the improvement of formulas, and the development of new recipes. They form the basis for the implementation of marketing strategies, such as the distribution of nutritional information among staff members and consumers. Furthermore, nutrient guidelines represent an essential part of food data bases which are the basis for nutrient analyses. The German Food Code and Nutrient Data Base (BLS = Bundeslebensmittelschlüssel Version II.3) - including raw ingredients, semi-finished food, convenience products and ready-to-eat meals - is linked up to the ingredients of recipes in almost all enterprise resource planning softwares.

As adequate amounts of nutrients available for the organism imply adequate amounts of nutrients contained in foods, it is of utmost importance to guarantee the best possible preservation of nutrients throughout all the steps of food processing. Thus, food processing plays a central role for the implementation of dietary guidelines.

\section{The Two Steps of Nutrient Optimization}

Nutrient optimization is composed of two steps, namely (1) optimization of nutrient and energy content of menus through a well-balanced diet composition, and (2) the best possible preservation of nutrients through professional food processing.

The first step is to revisit and evaluate existing meal plans based on the reference values of the target group. Subsequently, data are scrutinized for nutrient-optimizing possibilities with regard to the target group. After analyzing the improved menu plan, the new concept is to be implemented into practice (fig. 2) [6].

Nutrient content optimization in phase 1 :

- Rearrangement of menu plans

- Change of menus as a whole

- Change of menu components

- Improvement of existing recipes

- Change of certain ingredients

- Change in food composition

- Change of portion size

- Development of new recipes.

For the improvement and the development of new recipes it is necessary to consider that menus with an opti- 


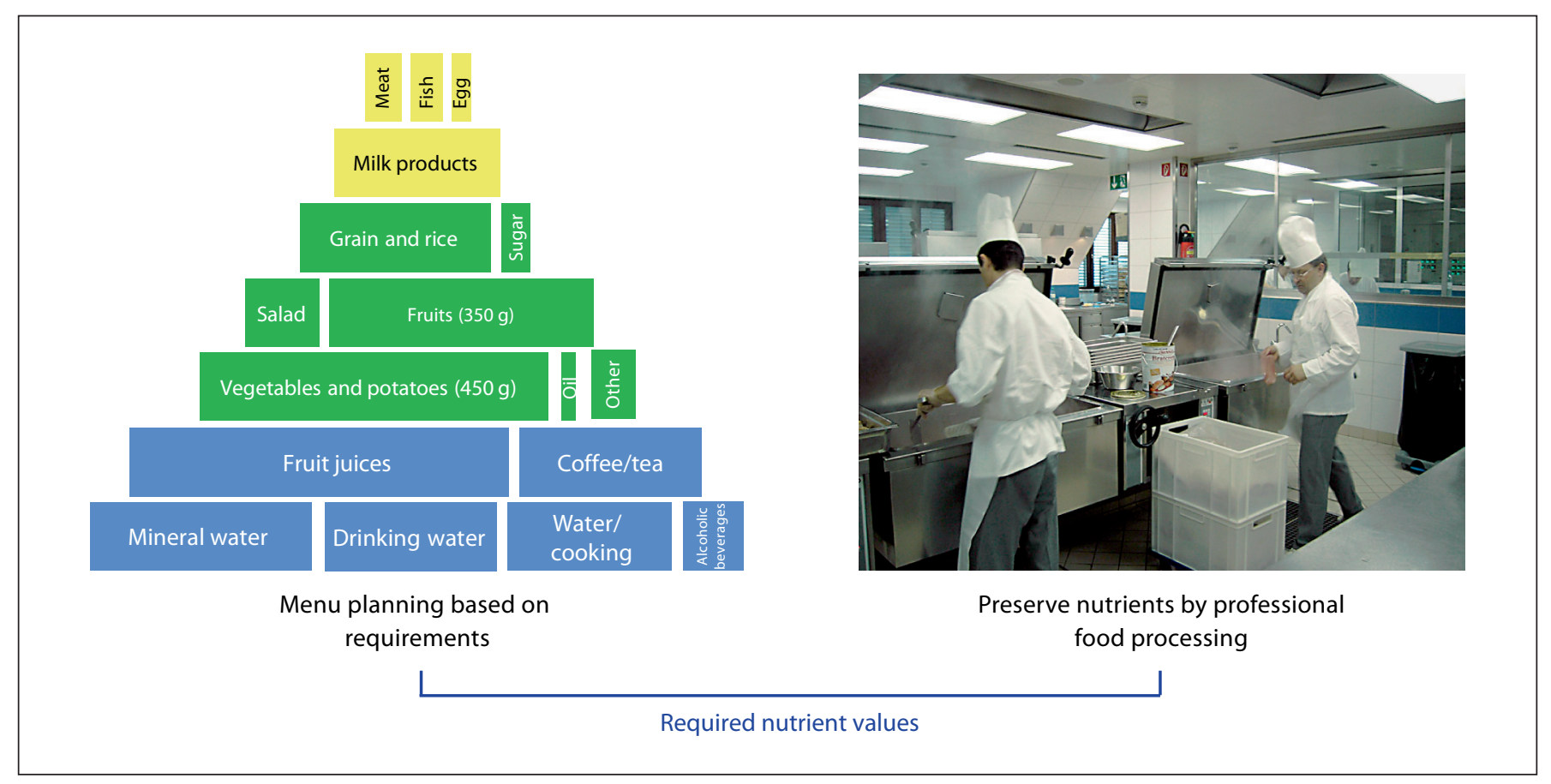

Fig. 2. Nutrient optimization concept [6].

mized health-promoting value still have to be tasty, otherwise these menus will not be chosen by the consumers. For the planning of menus it is advisable to avoid that these 'healthy meals' have to compete with favorite dishes that are poor in nutrients and high in energy.

Nutrient degradation occurs at all steps of food processing [7]. The identification and minimization of this nutrient loss during food processing - including all steps from purchase of raw materials to consumption of the prepared foods - represents phase II of nutrient optimization.

Promising approaches are the selection of ingredients, the storage, preparation, and cooking technologies, the organization of working processes, and the time for keeping the food warm. Skilled staff members play thereby an essential role.

Utilization of nutrient-preserving technologies:

- Protective packaging for stocking of intermediate products

- Cooking equipment with a big capacity for shortening the cook time

- Cooking equipment with automatic time and temperature monitoring and regulation

- Quick chilling systems for hot intermediate products

- Quick chilling systems for ready meals.
The potential for nutrient content optimization can be found at all steps of food processing: already during purchasing it is possible to consider the nutrient density of the raw ingredients. The ratio of fresh food to convenience food, as well as the level of processing of convenience food, has a considerable impact on the nutrient content of the prepared meal. Maintaining the cold chain is essential when taking over the goods. Ingredients delivered in damaged packages and goods nearing their expiry date usually show lower nutrient contents than fresh food. Short storage time of ingredients and optimal storage conditions (adequate temperature and humidity, light and oxygen shield) additionally improve the preservation of nutrients. Furthermore, packages should be sealed carefully again after opening.

The time between consecutive food preparation steps (e.g. peeling, cutting, etc.) should be kept as short as possible in order to protect intermediate products from external influences. Due to the large and unprotected surface area these semi-finished foods are increasingly subject to nutrient degradation caused by oxygen, light, and heat. Adequate cutting utilities prevent the additional squeezing of cells which can protect tissues against enzymatic degradation. 
Cooking equipment with automatic temperature monitoring and modern cooking technologies allow for a nutrient-sparing and fat-saving preparation of meals. Through the application of shock-cooling systems it is possible to avoid lengthy and nutrient-consuming storage at relatively high temperatures.

A nutrient optimization concept facilitates the practical application of the guidelines considering:

- Personnel to be made familiar with the applied concept

- A balanced relationship between health value and sensoric properties of the meals

- Nutrient optimization by improving menu planning and recipes

- High nutrient retention during food preparation

- Nutrition information for consumers.

Objective: to produce meals which are tasty and healthy.

The following resources and actions are necessary for the implementation of a nutrient optimization concept:

- Cooperation between nutritionists and cooks

- Education and information of the personnel involved (e.g. training of staff members)

- Use of food data bases for the justification of the choice

- Development of an adapted recipe book

- Adaptation of resources (time, staff, raw material) to the menu plan and the developed recipes

- Employment of nutrient-sparing technologies

- Implementation of quality management systems.

The sensoric properties and the health value of meals are equally considered at all steps of decision-making.

\section{The DGE (German Nutrition Society) and ÖGE (Austrian Nutrition Society) Award a Seal of Quality to Canteen Kitchens That Succeed in Improving the Nutritional Quality of Their Menus}

External evaluation and accreditation may act as a strong motivational signal for improving the health value of meals in community nutrition. This is especially true when nutrient optimization is required to gain a competitive edge in tendering procedures. Furthermore, the compliance with these regulations can be used as an internal management instrument. External quality requirements are often associated with public awards which strongly contribute to internal and external image building.

Major evaluation criteria for obtaining the DGE and ÖGE Seal of Quality are: (1) compliance with the DACH reference values for nutrient intake; (2) compliance with recipes throughout food processing, and (3) minimizing nutrient loss throughout meal preparation.

To summarize, community nutrition offers a wide range of possibilities to increase the health-promoting potential of meals. Nutrient-based intake recommendations act as the interface between theory and practice and form the basis for the development of recipes and professional menu planning. Thus, nutrient optimization requires a close cooperation between nutritionists and cooks. Nutrient calculation and food processing are vital for an adequate nutrient content of meals. Nutrient optimization in food needs to consider all areas of community nutrition including a target-group-oriented nutrient calculation, as well as planning and development of tasty and healthy meals and the highest possible nutrient retention during the entire food preparation process. External evaluation and accreditation play an important motivational role for nutrient optimization in community nutrition.

\section{References}

1 Statistik Austria, Statistisches Jahrbuch 2006. http://www.statistik.at/fachbereich_ 03/totenbeschau/allgemein.shtml

2 Elmadfa I, Freisling H: Österreichischer Ernährungsbericht 2003. Institut für Ernährungswissenschaften der Universität Wien, Bundesministerium für Gesundheit und Frauen, 2003.
3 Obergantschnig H: Küchenmanager als anerkannter Beruf. Studie Gemeinschaftsverpflegung, Gastro Obsearcher, Hotel und GV Praxis. Heft 1, Jan/Feb 2006.

4 Nohel CH, Payer H, Rützler H: 2. Lebensmittelbericht Österreich. Die Entwicklung des Lebensmittelsektors von 1995 bis 2002. Bundesministerium für Land und Forstwirtschaft, Juli 2003.

5 DGE, ÖGE, SGE, SVE: Die DACH-Referenzwerte für die Nährstoffzufuhr. Frankfurt am Main, Umschau Braus Verlagsgesellschaft, 2000.
6 Elmadfa I, Frisch G: Die Umsetzung der DACH-Referenzwerte für die Nährstoffzufuhr in der Gemeinschaftsverpflegung. Diplomarbeit am Institut für Ernährungswissenschaften, Universitätsbibliothek Wien, 2002.

7 AID: Nährstoffveränderungen bei der Lebensmittelzubereitung. Bonn 2004. 